\title{
Hedgehog and Gpr161: Regulating cAMP Signaling in the Primary Cilium
}

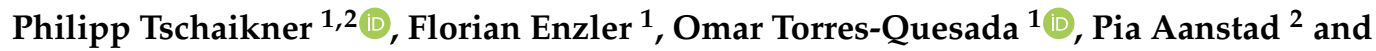 \\ Eduard Stefan $1, * \mathbb{D}$ \\ 1 Institute of Biochemistry and Center for Molecular Biosciences, University of Innsbruck, Innrain 80/82, \\ 6020 Innsbruck, Austria; philipp.tschaikner@uibk.ac.at (P.T.); florian.enzler@uibk.ac.at (F.E.); \\ omar.quesada@uibk.ac.at (O.T.-Q.) \\ 2 Institute of Molecular Biology, University of Innsbruck, 6020 Innsbruck, Austria; pia.aanstad@uibk.ac.at \\ * Correspondence: eduard.stefan@uibk.ac.at; Tel.: +43-512-507-57531; Fax: +43-512-507-57599
}

Received: 22 November 2019; Accepted: 29 December 2019; Published: 3 January 2020

\begin{abstract}
Compartmentalization of diverse types of signaling molecules contributes to the precise coordination of signal propagation. The primary cilium fulfills this function by acting as a spatiotemporally confined sensory signaling platform. For the integrity of ciliary signaling, it is mandatory that the ciliary signaling pathways are constantly attuned by alterations in both oscillating small molecules and the presence or absence of their sensor/effector proteins. In this context, ciliary G protein-coupled receptor (GPCR) pathways participate in coordinating the mobilization of the diffusible second messenger molecule $3^{\prime}, 5^{\prime}$-cyclic adenosine monophosphate (cAMP). cAMP fluxes in the cilium are primarily sensed by protein kinase A (PKA) complexes, which are essential for the basal repression of Hedgehog $(\mathrm{Hh})$ signaling. Here, we describe the dynamic properties of underlying signaling circuits, as well as strategies for second messenger compartmentalization. As an example, we summarize how receptor-guided cAMP-effector pathways control the off state of Hh signaling. We discuss the evidence that a macromolecular, ciliary-localized signaling complex, composed of the orphan GPCR Gpr161 and type I PKA holoenzymes, is involved in antagonizing Hh functions. Finally, we outline how ciliary cAMP-linked receptor pathways and cAMP-sensing signalosomes may become targets for more efficient combinatory therapy approaches to counteract dysregulation of Hh signaling.
\end{abstract}

Keywords: kinase; anchoring proteins; AKAP; orphan GPCR; signalosome; second messenger; cAMP; adenylyl cyclase; Hedgehog signaling; molecular interactions; dynamic complexes; signaling nodes; signaling circuits; compartmentalization

\section{Introduction}

Compartmentalization is an important aspect of intracellular signaling, both in contributing to the precise coordination of signal propagation and in ensuring specificity of signaling outcomes [1,2]. Primary cilia are microtubule-based antenna-like structures that extend from the plasma membrane, and represent a highly specialized subcellular compartment/environment for sensing and signaling [3,4]. The composition of the cilium, both in terms of signaling molecules, and also the lipid composition of the ciliary plasma membrane, is strictly regulated, with the transition zone operating to restrict diffusion and control trafficking in and out of the cilium [5]. The last couple of decades have seen an increased focus on, and understanding of, the role that cilia play in regulating signaling. This led to the identification of several signaling molecules, including G-protein coupled transmembrane receptors (GPCRs) and second messengers, that localize to cilia [3,6,7]. 
One central ciliary signaling component is the conserved and ubiquitous second messenger $3^{\prime}$, $5^{\prime}$-cyclic adenosine monophosphate (cAMP). First discovered by Sutherland and Rall in 1958, cAMP was proposed to act as a signal effector molecule downstream of hormones like epinephrine, dopamine, and prostaglandin [8]. Although this proposal was initially met with skepticism because it was difficult to see how the various actions of distinct hormones could all be mediated by a single effector molecule, we now know that second messengers like cAMP direct different cellular outcomes by interacting with different binding partners in distinct subcellular locations. Through cAMP-dependent protein kinase A (PKA), one of its primary targets, cAMP also plays a pivotal role in the regulation of Hedgehog (Hh) signaling in primary cilia $[5,9,10]$. This review will focus on the regulation and compartmentalization of cAMP in the primary cilium in the context of Hh signaling. We will first briefly describe the main effector molecules of cAMP, and how oscillations of cAMP fluxes are coordinated. Second, we discuss the function of PKA, the prototypical cAMP-effector, and one of the best studied examples for protein allostery and second messenger/protein interactions [11]. We discuss the role of spatiotemporal organization in receptor controlled kinase signaling by highlighting PKA signalosomes in, and at the base of, the primary cilium. Third, we describe the ways that Hh and the orphan receptor Gpr161 interact to regulate PKA activity and Hh signaling outcomes. In this context, we finally present an outlook of how these antagonizing signaling pathways in the primary cilium may become targets for combinatory pharmaceutical interference.

\section{2. cAMP Mobilization}

Intracellular cAMP mobilization is regulated by a family of adenylyl cyclases (ACs), which synthesize cAMP from adenosine triphosphate (ATP) (Figure 1) [12]. The activity of ACs is controlled by numerous extracellular cues, and mediates defined receptor-effector interactions. Prominent examples of extracellular stimuli and hormones activating ACs are epinephrine, dopamine, prostaglandin E2, and glucagon, which bind to defined cell surface receptors of the GPCR superfamily. GPCRs represent the largest family of cell surface molecules involved in signal transmission, and control a plethora of different cellular functions [13-15]. Here, we discuss GPCR coupling to the AC controlling $G$ proteins $G \alpha$ s and $G \alpha i$, which are part of the trimeric $G \alpha / \beta / \gamma G$ protein complex. On the molecular level, agonist binding to specific GPCRs leads to the activation of the AC-stimulatory G $\alpha$ s proteins [13,16-21]. In addition, AC-inhibitory GPCR pathways also exist (=G $\alpha$ i protein coupling), which contribute to reducing AC activities, and thus cAMP synthesis $[15,20,22]$. ACs synthesize cAMP from ATP by enzyme activities that are, in most cases, located on the inner side of the plasma membrane. This promotes spatiotemporally restricted cAMP oscillations, which are regulated and fine-tuned in different ways. One mechanism involves receptor complex desensitization, for switching off receptor activation at the plasma membrane. However, it should be noted that internalized receptor-effector complexes can engage in signal propagation and that receptor recycling and synthesis is critical for reactivation of signal transmission and oscillations [14,23-25]. Another way to limit the diffusion or abundance of cAMP is achieved by the presence and activation of phosphodiesterases (PDEs) [26-30]. Different PDEs mediate the breakdown of cAMP by hydrolyzing it to AMP [31]. Using visualization technologies, the existence of cell- and context-specific cAMP nanodomains has been demonstrated [32-40]. Spatially separated pools of cAMP are likely to be engaged in different functional outputs. This is based on the fact that a collection of different cAMP binding proteins and complexes exist. These cAMP sensing signalosomes differ in their composition, which is displayed by the cell type-specific availability of different isoforms and varying macromolecular complexes [11,41-45]. 


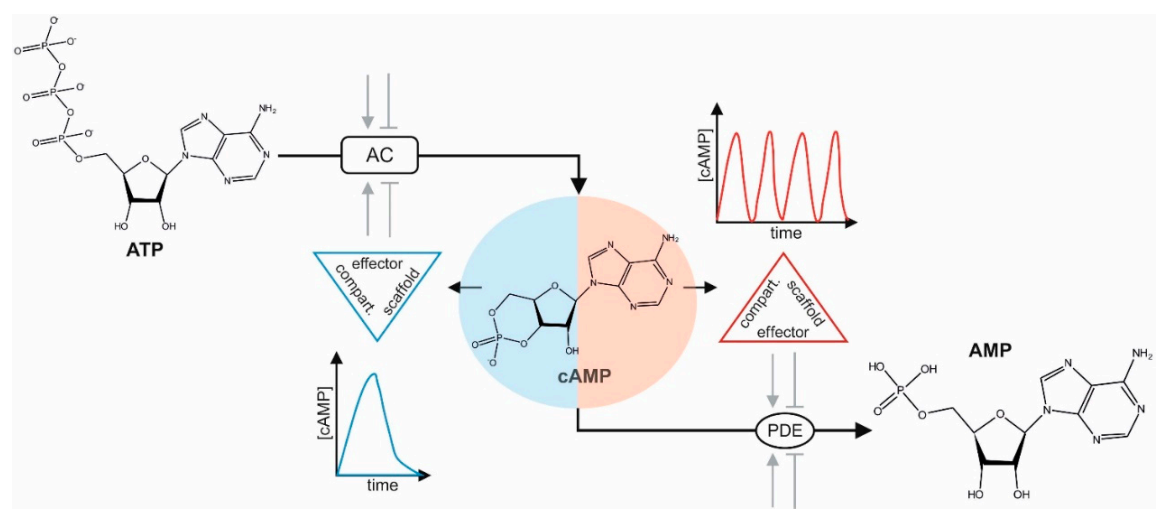

Figure 1. 3',5'-cyclic adenosine monophosphate (cAMP) dynamics. Different means modulate adenylyl cyclases (ACs) either positively or negatively (e.g., extracellular stimuli activate G-protein coupled transmembrane receptors (GPCRs) linked to G $\alpha$ s or G $\alpha \mathrm{i}$ ). Shown are the chemical structures of adenosine triphosphate (ATP), cAMP, and AMP. Spatiotemporal cAMP diffusion is restricted by the coordinated actions and dynamics of protein abundance, localization of receptor-controlled AC activities, phosphodiesterases (PDEs), cAMP-effectors, and physical barriers. Different compartmentalized scaffold-effector complexes (kinase/scaffold/PDE/AC) coordinate frequencies and peaks of cAMP oscillations in space and time.

\section{3. cAMP Dynamics: Sensors and Effectors}

Prime examples of cAMP-binding proteins are the functionally diverse type I and II holoenzyme complexes of PKA, isoforms of cAMP-dependent exchange proteins (Epac), cyclic nucleotide-gated ion channels (CNGs), and Popeye domain-containing proteins (POPDC) [34,35,46-49]. Before we discuss PKA, the prototype of an allosterically acting kinase complex and universal cAMP sensor, we briefly list the three other cAMP binding proteins. First, Epacs contain an evolutionally conserved cAMP-binding domain similar to PKA regulatory subunits (R). cAMP binding to Epac promotes activation of Rap, a small GTPase, which participates, among others, in the regulation of tumour cell invasion and metastasis via initiating of and/or interfering with ERK signaling [46,50-52]. Second, POPDC proteins contain functional cyclic nucleotide binding domains with cAMP binding affinities similar to PKA [53,54]. Mechanistic insights into cAMP binding functions are still elusive, but it is assumed that $\mathrm{CAMP}$ interactions with POPDC proteins trigger a conformational change and influences functional PPIs with, for example, TREK1-channels [48]. Third, cAMP binds to membrane localized CNGs to regulate their cation gating properties $[49,55]$. CNG functions are linked to signal transduction processes in olfactory receptor neurons [56]. In contrast to EPACs and POPDCs, which have not been directly linked to ciliary functions, CNGs localise to the membranes of specialized cilia of the olfactory sensory neurons, and thus are central for the translation of sensory cues into neuronal activity [57].

The prototypical and macromolecular cAMP-effector protein complex is nucleated by the tetrameric PKA holoenzyme [11,44]. Different compositions of these kinase holoenzymes mediate their functions in precise cell compartments and subcellular nanodomains. The core components are the PKA holoenzyme tetramers, which consist of two catalytic PKA subunits (C, PKAc), which interact with a dimer of identical regulatory PKA subunits (R). The cAMP-sensing $R$ homodimer blocks $C$ subunit activities by binding. Three genes for PKAc (coding for the proteins PKAc- $\alpha$, PKAc- $\beta$, and PKAc- $-\gamma$ ) and four genes for the R subunits (coding for the proteins $R I \alpha$, RI $\beta$, RII $\alpha$, and RII $\beta$ ) exist in the human genome [58-61]. The type I and II PKA R subunits are the nexus for cAMP-sensing and kinase activation, and are also responsible for the scaffold-mediated targeting of the holoenzyme to specific cAMP nanodomains. Distinct A kinase anchoring proteins (AKAPs) act as scaffolds to coordinate and ensure spatially and temporally restricted phosphorylation of substrates [2,41-43,45].

AKAPs sequester PKA holoenzymes to specific subcellular nanodomains. The structures of PKA type I and type II holoenzyme complexes differ considerably in their functions and solved structures [11,62-66]. 
Most AKAPs identified to date have been shown to be specific for type II holoenzymes. Moreover, it has been shown by several studies, using different kinase scaffolds, that type II PKA holoenzyme complex-specific AKAPs are often localized to subcellular organelles, including the nuclear envelope; the Golgi; and, for example, the cytoskeleton $[41,42,67]$. However, recently, two type I PKA selective AKAPs with low $\mathrm{nM}$ affinity for RI PKA subunits have been identified, the small AKAP smAKAP and the orphan GPCR Gpr161, respectively [45,68-70]. The function of the latter is discussed in the next section. However, the general principle of how AKAPs interact with PKA R subunit dimers is similar, based on a short interaction motif in the scaffold proteins. The conserved dimerization and docking domain $(D / D$ domain) of $\mathrm{R}$ subunits dimerizes and forms an anti-parallel X-type helical bundle, thereby creating a hydrophobic surface for AKAP binding [71,72]. All AKAPs identified so far share a short amphipathic $\alpha$-helix, which is composed of hydrophobic residues to diagonally dock the binding groove provided by the PKA R subunit dimer $[41-43,68,69,73]$. The majority of the so far more than 50 identified AKAPs have a modular organization and the capability to bind and compartmentalize combinations of kinase substrates, activator proteins, effector molecules, transduction, and termination enzymes. In Figure 2, we illustrate how AKAPs may function as broad signaling and scaffolding platforms for coordinating context-specific PPIs, as well as physical associations with PDEs, and the ubiquitin proteasome system (UPS) $[29,74]$. The AKAP-specific targeting domains recruit defined enzyme containing signalosomes to specific subcellular cell compartments. These actions are required to relay and restrict second messenger mediated signal transmission in a precise manner [41-43]. Compartmentalization of macromolecular kinase complexes to the plasma membrane, nucleus, mitochondria, endoplasmic reticulum, sarcoplasmic reticulum, primary cilium, or other distinct cellular organelles creates response specificity and guides the PKA-mediated information flow. Here, we would like to refer to reviews that describe the distinct subcellular localization of selected AKAPs and their interactions with, for example, additional kinases, phosphatases, PDEs, receptors, channels, ACs, Epacs, and other scaffolding proteins or factors relevant for GTPase involved signal propagation [2,35,41-43,67,75-77].

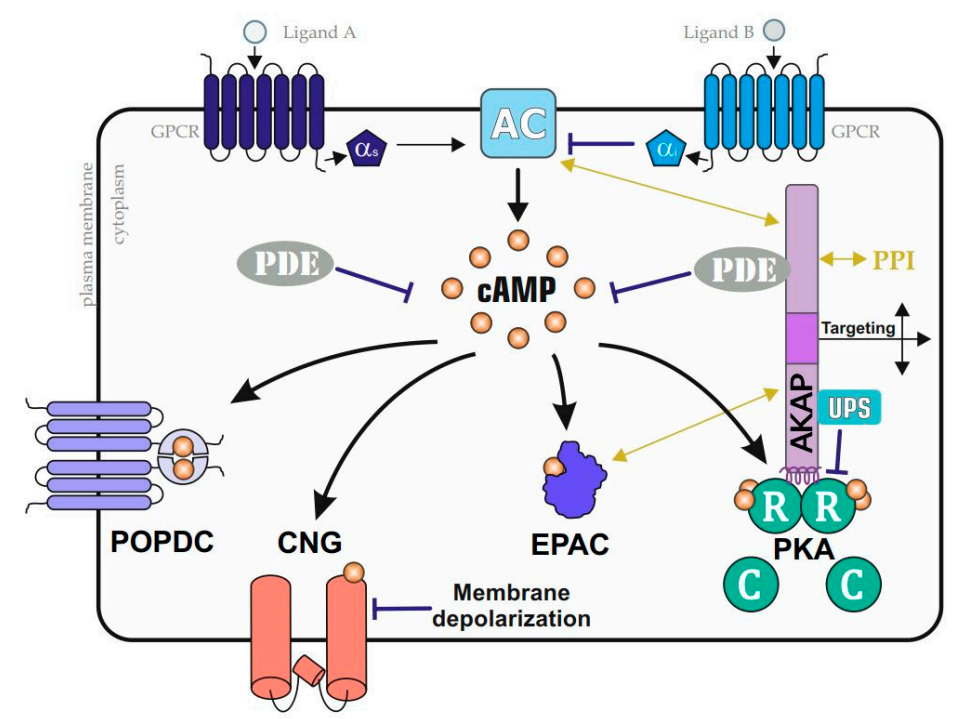

Figure 2. Prominent cAMP-effector pathways. A collection of GPCRs modulates adenylyl cyclase (AC) activities. AC stimulating or inactivating $G$ alpha proteins ( $\mathrm{G} \alpha \mathrm{s}$ or $\mathrm{G} \alpha \mathrm{i}$, respectively) control cAMP accumulation, which is sensed by a collection of indicated cAMP-binders. In addition to cytoplasmic cAMP-dependent exchange protein (Epac) and protein kinase A (PKA) complexes, membrane-bound cyclic nucleotide-gated ion (CNG) channels and Popeye domain-containing proteins (POPDC) proteins sense cAMP fluxes. PKA is compartmentalized by A kinase anchoring proteins (AKAPs), which coordinate the formation of cell- and context-specific subcellular PKA nanodomains through functional interactions with phosphodiesterases (PDEs); the ubiquitin proteasome system (UPS); and/or through additional PPIs (with, for example, ACs and Epacs), which are AKAP and nanodomain specific (indicated by the yellow arrows). 


\section{PKA and Hh in the Primary Cilium}

Nearly every cell in the body assembles one primary non-motile cilium. The primary cilium is an antennae-like, microtubule-based protrusion from the apical membrane of most mammalian cell types [78]. Dynamics and cAMP activation patterns in the cilium are functionally interwoven with Hh signaling in the vertebrate cilia. The Hh pathway is evolutionarily conserved and plays essential roles in cell fate specification and cell proliferation during embryonic development and in adult tissue homeostasis $[9,10,79]$. PKA is a central negative regulator of Hh signaling, which, in the absence of Hh ligands (= pathway off state), phosphorylates the Gli transcription factors to target them for proteolytic processing into transcriptional repressor forms (Gli-R). When Hh signaling is activated, the Hh pathway transducer protein Smoothened (Smo) translocates to the primary cilium, and promotes Hh signaling by inhibiting PKA activity, allowing the accumulation of full length Gli proteins, which can act as transcriptional activators (Gli-A) $[9,10]$. Hh functions as a morphogen, and directs distinct transcriptional outcomes depending on the concentration and time of exposure of responding cells to Hh [80]. The transcriptional outcome is determined by the ratio of Gli-R to Gli-A. In the absence of Hh, PKA activity is high. A partial reduction of PKA activity will reduce the production of Gli-R, and lead to activation of low level target genes, whereas complete inhibition of PKA activity is required for maximal level Hh target gene expression. Thus, the level of PKA activity determines the transcriptional outcome of Hh signaling, and a central aspect of Hh signal transduction is to fine-tune PKA activity to ensure the appropriate response (Figure 3) $[9,10,81]$.

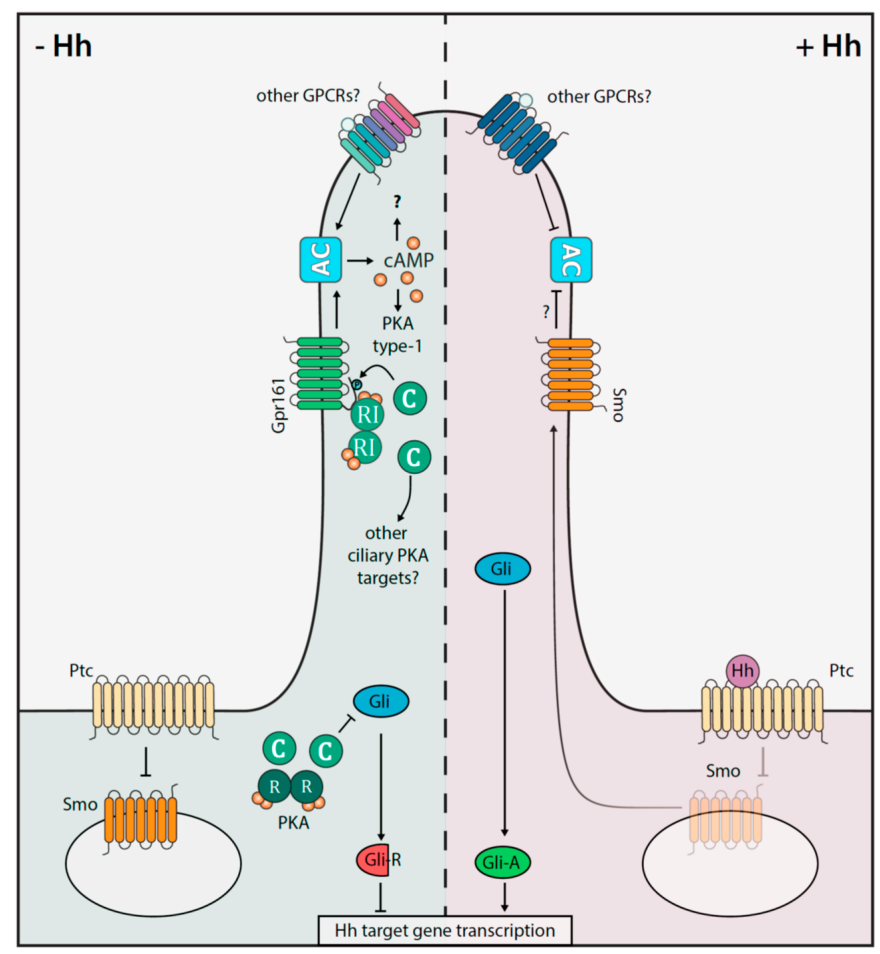

Figure 3. Interplay of the cAMP-PKA axis and Hh signaling in the primary cilium. Shown is a simplified depiction of the Hh on $(+\mathrm{Hh})$ and off $(-\mathrm{Hh})$ states in mammalian cells. Gpr161 and Smoothened (Smo) receptors act as key signal transducer. The involvement of other GPCRs, which impact cAMP and thus Hh signaling, are indicated. In the absence of the Hh ligand, Ptc inhibits Smo signaling. In a PKA dependent-manner, the repressor forms of Gli transcription factors (=Gli-R) are processed. Gli-R prevent the Hh directed gene expression profiles. Upon Hh binding to Ptc, activated Smo is recruited into the cilium, where it counteracts AC activities and Gpr161-PKA signalosomes are exported. The consequence is that the activated transcription factor Gli-A is enriched to promote Hh target gene expression. 


\section{The Gpr161-cAMP-PKA Signaling Axis in the Primary Cilium}

The primary cilium is essential for this response [82]. The core components of the Hh signaling pathway localize to cilia [9,83-85], which act as a platform for signal transduction and processing of the Gli transcription factors [4]. Thus, in mouse, loss of primary cilia leads to deregulation of Hh signaling, with a loss of high level target gene expression (Gli-A), and an expansion of low level target gene expression (loss of Gli-R) [4]. Initial work using immunohistochemistry showed that both PKA-C and the regulatory subunit RII $\beta$ localize to the base of the cilium, in the region around the basal body $[86,87]$, suggesting a model where PKA at the base of the cilium may phosphorylate the Gli transcription factors as they exit the cilium [87]. More recently, however, a proteomic analysis of the primary cilium identified the presence of both PKA-C, as well as the two regulatory subunits RI $\alpha$ and RII $\beta$, within the ciliary shaft [88]. Furthermore, these authors showed that targeting the PKA inhibitory peptide PKI to the primary cilium resulted in loss of processing of Gli, suggesting that PKA can act within the cilium to phosphorylate Gli for proteolytic processing $[5,88]$. One further interconnection between PKA abundance and Hh signalling involves the Rho GTPase activating protein ARHGAP36 [89].

The direct visualization of cAMP dynamics in the cilium has proved to be technically challenging, and measurements of resting cAMP levels in primary cilia vary [90-94]. Indirect evidence for activation of $\mathrm{AC}$ and elevation of cAMP levels in the primary cilium in the absence of Hh ligands is provided by studies on the involvement of GPCRs in the regulation of Hh signaling. The orphan G $\alpha$ s-coupled receptor Gpr161 has been shown to play a major role in antagonizing Hh signaling [95]. In the absence of Hh ligands, Gpr161 localizes to the primary cilium, where it couples to $G \alpha$ s to maintain high levels of cAMP and PKA activity. Activation of Hh signaling, as well as the ciliary translocation of Smo, induce the ciliary exit of Gpr161, thus effectively lowering the levels of ciliary cAMP [95]. Loss of Gpr161 results in hyperactivation of Hh signaling, although not to the same extent as a complete loss of PKA activity or a complete loss of G $\alpha$ s $[81,87,95]$, suggesting that additional GPCRs contribute to the activation of PKA and the maintenance of the basal Hh repression machinery [81]. Consistent with this, additional G protein coupled receptors, including Gpr175, Gpr17, and the chemokine receptor Cxcr4, have been shown to play a role in the regulation of Hh signaling [96-98]. However, Gpr161 is unique in this context, as, to date, it is the only GPCR shown to act as an AKAP [69]. The AKAP domain of Gpr161 is selective for type I holoenzymes, and has been shown to recruit cAMP binding RI $\alpha$ subunits to primary cilia of zebrafish embryos $[45,69]$. One possibility is that Gpr161 acts as an AKAP to recruit the whole type I PKA holoenzymes to the cilium for compartmentalized phosphorylation of the Gli transcription factors. In this scenario, Gpr161 would play a pivotal role in the negative regulation of Hh signaling, by ensuring the correct spatial localization of PKA, and also by regulating the activation of PKA by G $\alpha$ s-coupling and AC activation. However, type I PKA activities have a very narrow range and are thought to primarily phosphorylate targets that are in very close proximity $[11,99]$.

Interestingly, Gpr161 also contains a PKA consensus phosphorylation site, and has been shown to be a target for PKA phosphorylation [69]. This suggest that Gpr161 itself may be a major target for Gpr161-recruited ciliary type I PKA holoenzymes and may represent a further compartmentalization step within the cilium. The functional significance of PKA phosphorylation of ciliary compartmentalized Gpr161 is not known. However, phosphorylation of these GPCRs has been shown to alter activation state and/or subcellular localization, raising the possibility that PKA phosphorylation regulates ciliary Gpr161 activity and/or localization [69,100]. Alternatively, phosphorylation of Gpr161 may regulate the recruitment of further factors to form a macromolecular AKAP-kinase complex that contributes to regulation and fine-tuning of ciliary signal transmission. A cAMP-sensing Gpr161/PKA type I signalosome could thus be a platform for integrating and orchestrating ciliary cAMP oscillations and PKA activity in the regulation of Hh signaling. A better understanding of the interplay between Gpr161 and PKA in the cilium will require functional characterization of the AKAP and PKA phosphorylation mutants of Gpr161 and structural information about the organization of the Gpr161 signalosome complex. 
It is an open question if the cAMP-sensing Gpr161/PKA-type I signalosome is indeed the central platform for integrating and orchestrating ciliary cAMP fluxes, compartmentalized type I PKA activities, Gli processing, and Hh counter-regulation. The next major progress for shedding light on the underlying mechanism of ciliary Gpr161 function will be accomplished upon the identification of Gpr161 ligands. In addition, detailed structural information of the organization of the Gpr161-signalosome complex will be essential for understanding ciliary compartmentalization and its role in the basal repression of Hh signaling [6,101].

Recently, it has been shown that cAMP-induced PKA activities are not just central to Hh regulation. General cAMP fluxes have been linked to regulate cilium formation/removal. This is related to the recruitment of PKA and NIMA related kinase 10 (NEK10), a protein that is essential for ciliogenesis in vertebrates, to the pericentriolar matrix through the pericentriolar material protein 1 (PCM1). Thus, high cAMP levels lead to PKA-mediated phosphorylation of NEK10, which triggers its degradation and ultimately results in cilia resorption [102]. Interestingly, CHIP, the same ubiquitin ligase that marks NEK10 for degradation, is also involved during the regulation of PKAc levels in a negative feedback mechanism that acts to restrict PKA activation [103]. Similarly ARHGAP36 is also involved in limiting PKAc activity and abundance, which in turn regulates the depression of the Hh signaling pathway [89].

Cilia host a collection of GPCRs that are coupled to G $\alpha$ s or G $\alpha$ i. The following reviews summarize the identity of ciliary localized GPCRs [3,6,7] and one recent paper indicates the coupling of a selection of ciliary GPCRs [91]. Besides ligand availability, constitutive receptor activities, receptor abundance, and receptor desensitization, it is the import/export of the inventory of the ciliary cAMP platforms that affects Hh antagonizing effects of cAMP. AC3, AC5, and AC6 have been shown to be part of ciliary cAMP production machineries in vertebrates [5] and in response to regulatory input signals from the GPCRs. In this context, it is of major interest that, besides other signaling molecules, PDEs are also central components of AKAP-PKA complexes. In addition to AC activation, different PDE isoforms control cAMP oscillations in a nanodomain-specific manner in the sensory primary cilium compartment. Here, we would like to summarize the available evidence on PDE involvement. PDE1C has been identified in cilia of olfactory sensory neurons [104]. Moreover, PDE2 and guanylyl cyclases (GC) are also expressed in these cilia, where odorant GC-cGMP activation stimulates PDE2 to hydrolyze cAMP/cGMP $[105,106]$. Another PDE that is linked to cilium functions is the cGMP-dependent PDE6d, a prenyl-binding protein and chaperone of prenylated small $\mathrm{G}$ proteins, which is involved in the import of lipidated proteins into the primary cilium [107].

Further, a macromolecular protein complex comprising the ciliary calcium channel polycystin-2, AC5/6, PKA, PDE4c, and the A-kinase anchoring protein AKAP150 has been identified within the primary cilia of renal epithelial cells [108]. Polycystic kidney disease (PKD) is a genetic disorder characterized by the formation of cysts within the kidney tubules, which is caused by mutations that affect the molecular architecture of primary cilia [109]. It has been shown that PKD causing mutations of polycystin-2 led to dysregulated cAMP production within primary cilia. Therefore, cAMP signaling has been suggested to be a promising target for treatment strategies for PKD [108,110,111]. These results highlight that ciliary cAMP levels need to be tightly controlled to ensure healthy physiology, not only during Hh signaling.

\section{Perturbations of the cAMP and Hh Signaling at the Primary Cilium}

Hh regulates developmental and physiological cell/tissue states by supervising cell growth, survival, fate, and patterning [85,112]. In the Hh off-state, ciliary cAMP levels are elevated, which triggers the PKA-mediated proteolytic processing into Gli-R forms, which inhibits Hh target gene expression. Hh ligand availability advances the on-state. This leads to the ciliary accumulation of the central transducing component of the Hh signaling, which is the activated Smo receptor. The integrity of the $\mathrm{Hh}$ initiated signaling pathway is strongly associated with ciliary malfunctions. Diseases with cilium dysfunctions are termed ciliopathies. They are linked to mutations of a rising number of ciliopathy-associated genes [109]. A collection of developmental abnormalities is associated 
with syndromic ciliopathies. Two examples of compromised Hh signaling are polydactyly in the Bardet-Biedl syndrome and neural defects of the Meckel syndrome [109]. Many ciliopathies are caused by a disruption of the ciliogenic program. This may involve perturbations of gene expression, early ciliogenesis and the intraflagellar transport machinery, the formation of the transition zone, or the ciliary translocation of signaling components $[10,109]$. The central role of Smo as the key Hh signal transducer has focused attention on Smo in the work to develop therapeutic interventions. Especially in basal cell carcinoma or medulloblastoma, distinct somatic mutations promote the Hh pathway. Besides loss of function mutations in the negative Hh regulators Ptch and Sufu, activating mutations or amplifications in Smo and Gli protein variants also promote Hh signaling [113]. At this point, we would like to refer to reviews that precisely describe the collection of small molecule inhibitors and activators of the different components of the Hh signaling pathway [113-115]. A considerable number of Smo antagonists are either in clinical or preclinical trials. Two of the recently approved Smo inhibitors are Vismodegib (GDC-0449) and Sonidegib (Erismodegib). Overall, Smo inhibitors show promising antitumor effects against a variety of tumor types. However, there is increasing evidence that mutations in the pathway lead to acquired resistance mechanism [116].

The central role of PKA activity in the basal repression of Hh signaling is well documented. However, there is some ambiguity about how activation of Smo relieves the inhibitory effect on Gli-dependent transcriptional activation [9]. The underlying cell type-specific mechanistic details may depend on the spatiotemporal interplay, and the composition of several factors in and outside of the primary cilium. This also explains why we would rather pinpoint alternative or combinatory targeting strategies that should boost ciliary cAMP levels and PKA activation. There are pharmaceutical targets at different stages of the ciliary signaling axis, which involves diverse druggable components that influence cAMP dynamics. First, one explicit feature of the cilium is the high concentration of GPCRs that are accessible drug targets for intervening with the $G$ protein coupling and AC activation $[15,20]$. Comprehensive lists of ciliary GPCRs have been published that list either agonist or antagonists of these receptors that promote AC activation and ciliary cAMP production $[3,6,7,90,91,95,100]$. Second, recent advances in the development of isoform-selective AC inhibitors and activators suggest that ACs could serve as useful drug targets [117]. In this context, one interesting question would be how to target selectively cilium specific AC functions. Recent proof-of concept studies presented nanoparticle-based drug delivery approaches that can specifically target primary cilia in cell culture and animal models [118,119]. Third, the sole means of degrading cAMP are PDEs. They are critically involved in setting the subcellular cAMP concentration, and hence the PKA activity profile. Besides the inhibition of isoform-specific and cilium-enriched PDEs, enhancers of catalytic activity have also been successfully designed [30]. Antagonizing cilium-localized PDE functions may be one feasible strategy to elevate ciliary compartmentalized cAMP levels. Fourth, a collection of PKA-specific cAMP analogs are available. This fact needs to be considered for activating ciliary PKA type I or II holoenzymes, which may help to target scaffolding complexes with a precise enzyme composition [120,121].

Last, but not least, we envision that one specific GPCR may become an important candidate for antagonizing deregulated Hh signaling functions through cAMP mobilization. Gpr161 activities seem to be one of the long-sought factors for creating spatio-temporal controlled cAMP-gradients in the ciliary Hh signaling pathway $[6,122]$. Smo activation and ciliary accumulation lead to the clearance of Gpr161 from the cilium. So far, no ligands for Gpr161 have been identified. Indirect evidence suggests that it is coupled to G $\alpha$ s and subsequent cAMP elevation. We assume that this receptor might become a feasible target for elevating ciliary cAMP levels. Moreover, future research may reveal if the multimeric complex consisting of cAMP-sensing PKA and Gpr161 is the missing link and central ciliary signalosome to integrate and coordinate cAMP levels, compartmentalized PKA activities, Gli processing, and counteracting Smo signaling. Modulating Gpr161 functions using bioactive small molecules offers the unique opportunity to counteract decontrolled Hh signaling by engaging a ciliary and PKA-linked GPCR pathway. In light of a variety of ciliary dysfunctions 
and the drawbacks of Smo-directed therapies, we envision that implementing Gpr161 agonists into combination therapy-directed studies should improve the efficacy of Hh inhibition.

Author Contributions: Writing-original draft preparation, P.T., F.E., O.T.-Q., P.A., E.S.; writing-review and editing, P.T., P.A., E.S.; funding acquisition, P.A., E.S. All authors have read and agreed to the published version of the manuscript.

Funding: This research was funded by the Austrian science fund (FWF), grant numbers P27606, P27338, P30441, P32960.

Conflicts of Interest: The authors declare no conflict of interest.

\section{References}

1. Good, M.C.; Zalatan, J.G.; Lim, W.A. Scaffold proteins: Hubs for controlling the flow of cellular information. Science 2011, 332, 680-686. [CrossRef]

2. Scott, J.D.; Pawson, T. Cell signaling in space and time: Where proteins come together and when they're apart. Science 2009, 326, 1220-1224. [CrossRef]

3. Hilgendorf, K.I.; Johnson, C.T.; Jackson, P.K. The primary cilium as a cellular receiver: Organizing ciliary GPCR signaling. Curr. Opin. Cell Boil. 2016, 39, 84-92. [CrossRef]

4. Goetz, S.C.; Anderson, K.V. The primary cilium: A signalling centre during vertebrate development. Nat. Rev. Genet. 2010, 11, 331-344. [CrossRef]

5. Nachury, M.V.; Mick, D.U. Establishing and regulating the composition of cilia for signal transduction. Nat. Rev. Mol. Cell Boil. 2019, 20, 389-405. [CrossRef]

6. Schou, K.B.; Pedersen, L.B.; Christensen, S.T. Ins and outs of GPCR signaling in primary cilia. EMBO Rep. 2015, 16, 1099-1113. [CrossRef]

7. Mykytyn, K.; Askwith, C. G-Protein-Coupled Receptor Signaling in Cilia. Cold Spring Harb. Perspect. Boil. 2017, 9, a028183. [CrossRef]

8. Sutherland, E.W.; Rall, T.W. Fractionation and characterization of a cyclic adenine ribonucleotide formed by tissue particles. J. Boil. Chem. 1958, 232, 1077-1091.

9. Kong, J.H.; Siebold, C.; Rohatgi, R. Biochemical mechanisms of vertebrate hedgehog signaling. Development 2019, 146, dev166892. [CrossRef] [PubMed]

10. Briscoe, J.; Thérond, P.P. The mechanisms of Hedgehog signalling and its roles in development and disease. Nat. Rev. Mol. Cell Boil. 2013, 14, 416-429. [CrossRef] [PubMed]

11. Taylor, S.S.; Ilouz, R.; Zhang, P.; Kornev, A.P. Assembly of allosteric macromolecular switches: Lessons from PKA. Nat. Rev. Mol. Cell Boil. 2012, 13, 646-658. [CrossRef] [PubMed]

12. Sunahara, R.K.; Dessauer, C.W.; Gilman, A.G. Complexity and diversity of mammalian adenylyl cyclases. Annu. Rev. Pharmacol. Toxicol. 1996, 36, 461-480. [CrossRef] [PubMed]

13. Pierce, K.L.; Premont, R.T.; Lefkowitz, R.J. Seven-transmembrane receptors. Nat. Rev. Mol. Cell Boil. 2002, 3, 639-650. [CrossRef] [PubMed]

14. Rajagopal, S.; Rajagopal, K.; Lefkowitz, R.J. Teaching old receptors new tricks: Biasing seven-transmembrane receptors. Nat. Rev. Drug Discov. 2010, 9, 373-386. [CrossRef] [PubMed]

15. O'Hayre, M.; Degese, M.S.; Gutkind, J.S. Novel insights into G protein and G protein-coupled receptor signaling in cancer. Curr. Opin. Cell Boil. 2014, 27, 126-135. [CrossRef]

16. Sunahara, R.K. Isoforms of Mammalian Adenylyl Cyclase: Multiplicities of Signaling. Mol. Interv. 2002, 2, 168-184. [CrossRef]

17. Defer, N.; Best-Belpomme, M.; Hanoune, J. Tissue specificity and physiological relevance of various isoforms of adenylyl cyclase. Am. J. Physiol. Renal. Physiol. 2000, 279, 400-416. [CrossRef]

18. O’Hayre, M.; Vázquez-Prado, J.; Kufareva, I.; Stawiski, E.W.; Handel, T.M.; Seshagiri, S.; Gutkind, J.S. The emerging mutational landscape of $\mathrm{G}$ proteins and G-protein-coupled receptors in cancer. Nat. Rev. Cancer 2013, 13, 412-424. [CrossRef]

19. Tobin, A.B.; Butcher, A.J.; Kong, K.C. Location, location, location ... site-specific GPCR phosphorylation offers a mechanism for cell-type-specific signalling. Trends Pharmacol. Sci. 2008, 29, 413-420. [CrossRef]

20. Neves, S.R.; Ram, P.T.; Iyengar, R. G Protein Pathways. Science 2002, 296, 1636-1639. [CrossRef] 
21. Stefan, E.; Malleshaiah, M.K.; Breton, B.; Ear, P.H.; Bachmann, V.; Beyermann, M.; Bouvier, M.; Michnick, S.W. PKA regulatory subunits mediate synergy among conserved G-protein-coupled receptor cascades. Nat. Commun. 2011, 2, 598. [CrossRef] [PubMed]

22. Dorsam, R.T.; Gutkind, J.S. G-protein-coupled receptors and cancer. Nat. Rev. Cancer 2007, 7, 79-94. [CrossRef] [PubMed]

23. Lohse, M.J.; Maiellaro, I.; Calebiro, D. Kinetics and mechanism of G protein-coupled receptor activation. Curr. Opin. Cell Boil. 2014, 27, 87-93. [CrossRef] [PubMed]

24. Thomsen, A.R.B.; Plouffe, B.; Cahill, T.J., 3rd; Shukla, A.K.; Tarrasch, J.T.; Dosey, A.M.; Kahsai, A.W.; Strachan, R.T.; Pani, B.; Mahoney, J.P.; et al. Gpcr-g protein-beta-arrestin super-complex mediates sustained g protein signaling. Cell 2016, 166, 907-919. [CrossRef]

25. Mohan, M.L.; Vasudevan, N.T.; Gupta, M.K.; Martelli, E.E.; Prasad, S.V.N. G-protein coupled receptor resensitization-appreciating the balancing act of receptor function. Curr. Mol. Pharmacol. 2012, 5, 350-361. [CrossRef]

26. Conti, M.; Beavo, J. Biochemistry and Physiology of Cyclic Nucleotide Phosphodiesterases: Essential Components in Cyclic Nucleotide Signaling. Annu. Rev. Biochem. 2007, 76, 481-511. [CrossRef]

27. Maurice, D.H.; Ke, H.; Ahmad, F.; Wang, Y.; Chung, J.; Manganiello, V.C. Advances in targeting cyclic nucleotide phosphodiesterases. Nat. Rev. Drug Discov. 2014, 13, 290-314. [CrossRef]

28. Baillie, G.S. Compartmentalized signalling: Spatial regulation of cAMP by the action of compartmentalized phosphodiesterases. FEBS J. 2009, 276, 1790-1799. [CrossRef]

29. Houslay, M.D.; Baillie, G.S.; Maurice, D.H. Camp-specific phosphodiesterase-4 enzymes in the cardiovascular system: A molecular toolbox for generating compartmentalized camp signaling. Circ. Res. 2007, 100, 950-966. [CrossRef]

30. Baillie, G.S.; Tejeda, G.S.; Kelly, M.P. Therapeutic targeting of 3' $5^{\prime}$-cyclic nucleotide phosphodiesterases: Inhibition and beyond. Nat. Rev. Drug Discov. 2019, 18, 770-796. [CrossRef]

31. Houslay, M.D. Underpinning compartmentalised camp signalling through targeted camp breakdown. Trends Biochem. Sci. 2009, 35, 91-100. [CrossRef] [PubMed]

32. Musheshe, N.; Schmidt, M.; Zaccolo, M. cAMP: From Long-Range Second Messenger to Nanodomain Signalling. Trends Pharmacol. Sci. 2018, 39, 209-222. [CrossRef] [PubMed]

33. Lissandron, V.; Zaccolo, M. Compartmentalized cAMP/PKA signalling regulates cardiac excitationcontraction coupling. J. Muscle Res. Cell Motil. 2006, 27, 399-403. [CrossRef] [PubMed]

34. Dessauer, C.W. Adenylyl cyclase-A-kinase anchoring protein complexes: The next dimension in cAMP signaling. Mol. Pharmacol. 2009, 76, 935-941. [CrossRef] [PubMed]

35. Scott, J.D.; Dessauer, C.W.; Tasken, K. Creating order from chaos: Cellular regulation by kinase anchoring. Annu. Rev. Pharmacol. Toxicol. 2013, 53, 187-210. [CrossRef]

36. Jiang, J.Y.; Falcone, J.L.; Curci, S.; Hofer, A.M. Interrogating cyclic AMP signaling using optical approaches. Cell Calcium 2017, 64, 47-56. [CrossRef]

37. Castro, L.R.V.; Guiot, E.; Polito, M.; Vincent, P.; Paupardin-Tritsch, D. Decoding spatial and temporal features of neuronal cAMP/PKA signaling with FRET biosensors. Biotechnol. J. 2014, 9, 192-202. [CrossRef]

38. Calebiro, D.; Nikolaev, V.O.; Gagliani, M.C.; De Filippis, T.; Dees, C.; Tacchetti, C.; Persani, L.; Lohse, M.J. Persistent cAMP-signals triggered by internalized G-protein-coupled receptors. PLoS Boil. 2009, 7, e1000172. [CrossRef]

39. Clister, T.; Greenwald, E.C.; Baillie, G.S.; Zhang, J. AKAP95 Organizes a Nuclear Microdomain to Control Local cAMP for Regulating Nuclear PKA. Cell Chem. Boil. 2019, 26, 885-891. [CrossRef]

40. Sprenger, J.U.; Nikolaev, V.O. Biophysical techniques for detection of camp and cgmp in living cells. Int. J. Mol. Sci. 2013, 14, 8025-8046. [CrossRef]

41. Langeberg, L.K.; Scott, J.D. Signalling scaffolds and local organization of cellular behaviour. Nat. Rev. Mol. Cell Boil. 2015, 16, 232-244. [CrossRef] [PubMed]

42. Wong, W.; Scott, J.D. AKAP signalling complexes: Focal points in space and time. Nat. Rev. Mol. Cell Boil. 2004, 5, 959-970. [CrossRef]

43. Skroblin, P.; Grossmann, S.; Schäfer, G.; Rosenthal, W.; Klussmann, E. Mechanisms of Protein Kinase A Anchoring. Int. Rev. Cell Mol. Biol. 2010, 283, 235-330. [PubMed]

44. Taylor, S.S.; Zhang, P.; Steichen, J.M.; Keshwani, M.M.; Kornev, A.P. PKA: Lessons learned after twenty years. Biochim. Biophys. Acta (BBA) Bioenerg. 2013, 1834, 1271-1278. [CrossRef] [PubMed] 
45. Torres-Quesada, O.; Mayrhofer, J.E.; Stefan, E. The many faces of compartmentalized PKA signalosomes. Cell. Signal. 2017, 37, 1-11. [CrossRef] [PubMed]

46. Gloerich, M.; Bos, J.L. Epac: Defining a New Mechanism for cAMP Action. Annu. Rev. Pharmacol. Toxicol. 2010, 50, 355-375. [CrossRef] [PubMed]

47. Bradley, J.; Reisert, J.; Frings, S. Regulation of cyclic nucleotide-gated channels. Curr. Opin. Neurobiol. 2005, 15, 343-349. [CrossRef]

48. Brand, T. The Popeye Domain Containing Genes and Their Function as cAMP Effector Proteins in Striated Muscle. J. Cardiovasc. Dev. Dis. 2018, 5, 18. [CrossRef]

49. Kaupp, U.B.; Seifert, R. Cyclic nucleotide-gated ion channels. Physiol Rev. 2002, 82, 769-824. [CrossRef]

50. Shah, S.; Brock, E.J.; Ji, K.; Mattingly, R.R. Ras and Rap1: A tale of two GTPases. Semin. Cancer Boil. 2019, 54, 29-39. [CrossRef]

51. Takahashi, M.; Li, Y.; Dillon, T.J.; Stork, P.J.S. Phosphorylation of rap1 by camp-dependent protein kinase (pka) creates a binding site for ksr to sustain erk activation by camp. J. Biol. Chem. 2017, 292, 1449-1461. [CrossRef] [PubMed]

52. Li, Y.; Dillon, T.J.; Takahashi, M.; Earley, K.T.; Stork, P.J.S. Protein Kinase A-independent Ras Protein Activation Cooperates with Rap1 Protein to Mediate Activation of the Extracellular Signal-regulated Kinases (ERK) by cAMP. J. Boil. Chem. 2016, 291, 21584-21595. [CrossRef] [PubMed]

53. Froese, A.; Breher, S.S.; Waldeyer, C.; Schindler, R.F.; Nikolaev, V.O.; Rinné, S.; Wischmeyer, E.; Schlueter, J.; Becher, J.; Simrick, S.; et al. Popeye domain containing proteins are essential for stress-mediated modulation of cardiac pacemaking in mice. J. Clin. Investig. 2012, 122, 1119-1130. [CrossRef] [PubMed]

54. Schindler, R.F.R.; Brand, T. The Popeye domain containing protein family-A novel class of cAMP effectors with important functions in multiple tissues. Prog. Biophys. Mol. Boil. 2016, 120, 28-36. [CrossRef]

55. Liman, E.R.; Buck, L.B. A second subunit of the olfactory cyclic nucleotide-gated channel confers high sensitivity to cAMP. Neuron 1994, 13, 611-621. [CrossRef]

56. Bradley, J.; Li, J.; Davidson, N.; Lester, H.A.; Zinn, K. Heteromeric olfactory cyclic nucleotide-gated channels: A subunit that confers increased sensitivity to cAMP. Proc. Natl. Acad. Sci. USA 1994, 91, 8890-8894. [CrossRef]

57. Falk, N.; Lösl, M.; Schröder, N.; Gießl, A. Specialized Cilia in Mammalian Sensory Systems. Cells 2015, 4, 500-519. [CrossRef]

58. Scott, J.D.; Stofko, R.E.; McDonald, J.R.; Comer, J.D.; Vitalis, E.A.; Mangili, J.A. Type II regulatory subunit dimerization determines the subcellular localization of the cAMP-dependent protein kinase. J. Boil. Chem. 1990, 265, 21561-21566.

59. Taskén, K.; Skålhegg, B.S.; Solberg, R.; Andersson, K.B.; Taylor, S.S.; Lea, T.; Blomhoff, H.K.; Jahnsen, T.; Hansson, V. Novel isozymes of cAMP-dependent protein kinase exist in human cells due to formation of RI alpha-RI beta heterodimeric complexes. J. Boil. Chem. 1993, 268, 21276-21283.

60. Turnham, R.E.; Scott, J.D. Protein kinase a catalytic subunit isoform prkaca; history, function and physiology. Gene 2016, 577, 101-108. [CrossRef]

61. Skalhegg, B.S.; Tasken, K. Specificity in the camp/pka signaling pathway. Differential expression, regulation, and subcellular localization of subunits of pka. Front. Biosci. 2000, 5, D678-D693. [PubMed]

62. Herberg, F.W.; Taylor, S.S.; Dostmann, W.R.G. Active Site Mutations Define the Pathway for the Cooperative Activation of cAMP-Dependent Protein Kinase. Biochemistry 1996, 35, 2934-2942. [CrossRef] [PubMed]

63. Solberg, R.; Tasken, K.; Wen, W.; Coghlan, V.M.; Meinkoth, J.L.; Scott, J.D.; Jahnsen, T.; Taylor, S.S. Human regulatory subunit ri beta of camp-dependent protein kinases: Expression, holoenzyme formation and microinjection into living cells. Exp. Cell Res. 1994, 214, 595-605. [CrossRef] [PubMed]

64. Wu, J.; Brown, S.H.J.; Von Daake, S.; Taylor, S.S. PKA type Ilalpha holoenzyme reveals a combinatorial strategy for isoform diversity. Science 2007, 318, 274-279. [CrossRef] [PubMed]

65. Zawadzki, K.M.; Taylor, S.S. Camp-dependent protein kinase regulatory subunit type iibeta: Active site mutations define an isoform-specific network for allosteric signaling by camp. J. Biol. Chem. 2004, 279, 7029-7036. [CrossRef] [PubMed]

66. Kim, C.; Xuong, N.H.; Taylor, S.S. Crystal structure of a complex between the catalytic and regulatory (rialpha) subunits of pka. Science 2005, 307, 690-696. [CrossRef]

67. Taskén, K.; Aandahl, E.M. Localized Effects of cAMP Mediated by Distinct Routes of Protein Kinase A. Physiol. Rev. 2004, 84, 137-167. [CrossRef] 
68. Burgers, P.P.; Bruystens, J.; Burnley, R.J.; Nikolaev, V.O.; Keshwani, M.; Wu, J.; Janssen, B.J.C.; Taylor, S.S.; Heck, A.J.R.; Scholten, A. Structure of smAKAP and its regulation by PKA-mediated phosphorylation. FEBS J. 2016, 283, 2132-2148. [CrossRef]

69. Bachmann, V.A.; Mayrhofer, J.E.; Ilouz, R.; Tschaikner, P.; Raffeiner, P.; Rock, R.; Courcelles, M.; Apelt, F.; Lu, T.-W.; Baillie, G.S.; et al. Gpr161 anchoring of PKA consolidates GPCR and cAMP signaling. Proc. Natl. Acad. Sci. USA 2016, 113, 7786-7791. [CrossRef]

70. Burgers, P.P.; Ma, Y.; Margarucci, L.; Mackey, M.; Van Der Heyden, M.A.G.; Ellisman, M.; Scholten, A.; Taylor, S.S.; Heck, A.J.R. A Small Novel A-Kinase Anchoring Protein (AKAP) That Localizes Specifically Protein Kinase A-Regulatory Subunit I (PKA-RI) to the Plasma Membrane. J. Boil. Chem. 2012, 287, 43789-43797. [CrossRef]

71. Banky, P. Dimerization/Docking Domain of the Type Ialpha Regulatory Subunit of cAMP-dependent Protein Kinase. REQUIREMENTS FOR DIMERIZATION AND DOCKING ARE DISTINCT BUT OVERLAPPING. J. Boil. Chem. 1998, 273, 35048-35055. [CrossRef] [PubMed]

72. Kinderman, F.S.; Kim, C.; Von Daake, S.; Ma, Y.; Pham, B.Q.; Spraggon, G.; Xuong, N.-H.; Jennings, P.A.; Taylor, S.S. A dynamic mechanism for AKAP binding to RII isoforms of cAMP-dependent protein kinase. Mol. Cell 2006, 24, 397-408. [CrossRef] [PubMed]

73. Pawson, C.T.; Scott, J.D. Signal integration through blending, bolstering and bifurcating of intracellular information. Nat. Struct. Mol. Boil. 2010, 17, 653-658. [CrossRef] [PubMed]

74. Rinaldi, L.; Sepe, M.; Donne, R.D.; Feliciello, A. A dynamic interface between ubiquitylation and cAMP signaling. Front. Pharmacol. 2015, 6, 177. [CrossRef]

75. Welch, E.J.; Jones, B.W.; Scott, J.D. Networking with AKAPs: Context-dependent regulation of anchored enzymes. Mol. Interv. 2010, 10, 86-97. [CrossRef]

76. Malbon, C.C.; Tao, J.; Wang, H.-Y. AKAPs (A-kinase anchoring proteins) and molecules that compose their G-protein-coupled receptor signalling complexes. Biochem. J. 2004, 379, 1-9. [CrossRef]

77. Calejo, A.I.; Tasken, K. Targeting protein-protein interactions in complexes organized by a kinase anchoring proteins. Front. Pharmacol. 2015, 6, 192. [CrossRef]

78. Johnson, C.A.; Malicki, J.J. The Nuclear Arsenal of Cilia. Dev. Cell 2019, 49, 161-170. [CrossRef]

79. Ingham, P.W.; Nakano, Y.; Seger, C. Mechanisms and functions of Hedgehog signalling across the metazoa. Nat. Rev. Genet. 2011, 12, 393-406. [CrossRef]

80. Dessaud, E.; McMahon, A.P.; Briscoe, J. Pattern formation in the vertebrate neural tube: A sonic hedgehog morphogen-regulated transcriptional network. Development 2008, 135, 2489-2503. [CrossRef]

81. Pusapati, G.V.; Kong, J.H.; Patel, B.B.; Gouti, M.; Sagner, A.; Sircar, R.; Luchetti, G.; Ingham, P.W.; Briscoe, J.; Rohatgi, R. G protein-coupled receptors control the sensitivity of cells to the morphogen Sonic Hedgehog. Sci. Signal. 2018, 11, eaao5749. [CrossRef] [PubMed]

82. Huangfu, D.; Anderson, K.V. Signaling from Smo to Ci/Gli: Conservation and divergence of Hedgehog pathways from Drosophila to vertebrates. Development 2006, 133, 3-14. [CrossRef] [PubMed]

83. Corbit, K.C.; Aanstad, P.; Singla, V.; Norman, A.R.; Stainier, D.Y.R.; Reiter, J.F. Vertebrate Smoothened functions at the primary cilium. Nature 2005, 437, 1018-1021. [CrossRef] [PubMed]

84. Haycraft, C.J.; Banizs, B.; Aydin-Son, Y.; Zhang, Q.; Michaud, E.J.; Yoder, B.K. Gli2 and gli3 localize to cilia and require the intraflagellar transport protein polaris for processing and function. PLoS Genet. 2005, 1, e53. [CrossRef]

85. Rohatgi, R.; Milenkovic, L.; Scott, M.P. Patched1 Regulates Hedgehog Signaling at the Primary Cilium. Science 2007, 317, 372-376. [CrossRef]

86. Barzi, M.; Berenguer, J.; Menendez, A.; Alvarez-Rodriguez, R.; Pons, S. Sonic-hedgehog-mediated proliferation requires the localization of pka to the cilium base. J. Cell Sci. 2010, 123, 62-69. [CrossRef]

87. Tuson, M.; He, M.; Anderson, K.V. Protein kinase A acts at the basal body of the primary cilium to prevent Gli2 activation and ventralization of the mouse neural tube. Development 2011, 138, 4921-4930. [CrossRef]

88. Mick, D.U.; Rodrigues, R.B.; Leib, R.D.; Adams, C.M.; Chien, A.S.; Gygi, S.P.; Nachury, M.V. Proteomics of Primary Cilia by Proximity Labeling. Dev. Cell 2015, 35, 497-512. [CrossRef]

89. Eccles, R.L.; Czajkowski, M.T.; Barth, C.; Müller, P.M.; McShane, E.; Grunwald, S.; Beaudette, P.; Mecklenburg, N.; Volkmer, R.; Zühlke, K.; et al. Bimodal antagonism of PKA signalling by ARHGAP36. Nat. Commun. 2016, 7, 12963. [CrossRef] 
90. Moore, B.S.; Stepanchick, A.N.; Tewson, P.H.; Hartle, C.M.; Zhang, J.; Quinn, A.M.; Hughes, T.E.; Mirshahi, T. Cilia have high cAMP levels that are inhibited by Sonic Hedgehog-regulated calcium dynamics. Proc. Natl. Acad. Sci. USA 2016, 113, 13069-13074. [CrossRef]

91. Jiang, J.Y.; Falcone, J.L.; Curci, S.; Hofer, A.M. Direct visualization of cAMP signaling in primary cilia reveals up-regulation of ciliary GPCR activity following Hedgehog activation. Proc. Natl. Acad. Sci. USA 2019, 116, 12066-12071. [CrossRef] [PubMed]

92. Mukherjee, S.; Jansen, V.; Jikeli, J.F.; Hamzeh, H.; Alvarez, L.; Dombrowski, M.; Balbach, M.; Strünker, T.; Seifert, R.; Kaupp, U.B.; et al. A novel biosensor to study cAMP dynamics in cilia and flagella. eLife 2016, 5, 694. [CrossRef] [PubMed]

93. Marley, A.; Choy, R.W.-Y.; Von Zastrow, M. GPR88 Reveals a Discrete Function of Primary Cilia as Selective Insulators of GPCR Cross-Talk. PLoS ONE 2013, 8, e70857. [CrossRef] [PubMed]

94. Sherpa, R.T.; Mohieldin, A.M.; Pala, R.; Wachten, D.; Ostrom, R.S.; Nauli, S.M. Sensory primary cilium is a responsive cAMP microdomain in renal epithelia. Sci. Rep. 2019, 9, 6523. [CrossRef]

95. Mukhopadhyay, S.; Wen, X.; Ratti, N.; Loktev, A.; Rangell, L.; Scales, S.J.; Jackson, P.K. The Ciliary G-Protein-Coupled Receptor Gpr161 Negatively Regulates the Sonic Hedgehog Pathway via cAMP Signaling. Cell 2013, 152, 210-223. [CrossRef]

96. Yatsuzuka, A.; Hori, A.; Kadoya, M.; Matsuo-Takasaki, M.; Kondo, T.; Sasai, N. GPR17 is an essential regulator for the temporal adaptation of sonic hedgehog signalling in neural tube development. Development 2019, 146, dev176784. [CrossRef]

97. Singh, J.; Wen, X.; Scales, S.J. The Orphan G Protein-coupled Receptor Gpr175 (Tpra40) Enhances Hedgehog Signaling by Modulating cAMP Levels. J. Boil. Chem. 2015, 290, 29663-29675. [CrossRef]

98. Stückemann, T.; Wegleiter, T.; Stefan, E.; Nägele, O.; Tarbashevich, K.; Böck, G.; Raz, E.; Aanstad, P. Zebrafish Cxcr4a determines the proliferative response to Hedgehog signalling. Development 2012, 139, 2711-2720. [CrossRef]

99. Diskar, M.; Zenn, H.-M.; Kaupisch, A.; Prinz, A.; Herberg, F.W. Molecular basis for isoform-specific autoregulation of protein kinase A. Cell. Signal. 2007, 19, 2024-2034. [CrossRef]

100. Pal, K.; Hwang, S.H.; Somatilaka, B.; Badgandi, H.; Jackson, P.K.; DeFea, K.; Mukhopadhyay, S. Smoothened determines beta-arrestin-mediated removal of the $\mathrm{g}$ protein-coupled receptor gpr161 from the primary cilium. J. Cell Biol. 2016, 212, 861-875. [CrossRef]

101. Fliegauf, M.; Benzing, T.; Omran, H. When cilia go bad: Cilia defects and ciliopathies. Nat. Rev. Mol. Cell Boil. 2007, 8, 880-893. [CrossRef] [PubMed]

102. Porpora, M.; Sauchella, S.; Rinaldi, L.; Donne, R.D.; Sepe, M.; Torres-Quesada, O.; Intartaglia, D.; Garbi, C.; Insabato, L.; Santoriello, M.; et al. Counterregulation of cAMP-directed kinase activities controls ciliogenesis. Nat. Commun. 2018, 9, 1224. [CrossRef] [PubMed]

103. Rinaldi, L.; Donne, R.D.; Catalanotti, B.; Torres-Quesada, O.; Enzler, F.; Moraca, F.; Nisticò, R.; Chiuso, F.; Piccinin, S.; Bachmann, V.; et al. Feedback inhibition of cAMP effector signaling by a chaperone-assisted ubiquitin system. Nat. Commun. 2019, 10, 2572. [CrossRef] [PubMed]

104. Cygnar, K.D.; Zhao, H. Phosphodiesterase $1 \mathrm{C}$ is dispensable for rapid response termination of olfactory sensory neurons. Nat. Neurosci. 2009, 12, 454-462. [CrossRef]

105. Bian, K.; Ghassemi, F.; Sotolongo, A.; Siu, A.; Shauger, L.; Kots, A.; Murad, F. NOS-2 signaling and cancer therapy. IUBMB Life 2012, 64, 676-683. [CrossRef]

106. Aye, T.T.; Soni, S.; Van Veen, T.A.; Van Der Heyden, M.A.; Cappadona, S.; Varró, A.; De Weger, R.A.; De Jonge, N.; Vos, M.A.; Heck, A.J.; et al. Reorganized PKA-AKAP associations in the failing human heart. J. Mol. Cell. Cardiol. 2012, 52, 511-518. [CrossRef]

107. Humbert, M.C.; Weihbrecht, K.; Searby, C.C.; Li, Y.; Pope, R.M.; Sheffield, V.C.; Seo, S. ARL13B, PDE6D, and CEP164 form a functional network for INPP5E ciliary targeting. Proc. Natl. Acad. Sci. USA 2012, 109, 19691-19696. [CrossRef]

108. Choi, Y.-H.; Suzuki, A.; Hajarnis, S.; Ma, Z.; Chapin, H.C.; Caplan, M.J.; Pontoglio, M.; Somlo, S.; Igarashi, P. Polycystin-2 and phosphodiesterase $4 \mathrm{C}$ are components of a ciliary A-kinase anchoring protein complex that is disrupted in cystic kidney diseases. Proc. Natl. Acad. Sci. USA 2011, 108, 10679-10684. [CrossRef]

109. Reiter, J.F.; Leroux, M.R. Genes and molecular pathways underpinning ciliopathies. Nat. Rev. Mol. Cell Boil. 2017, 18, 533-547. [CrossRef] 
110. Calvet, J.P. The Role of Calcium and Cyclic AMP in PKD. In Polycystic Kidney Disease; Li, X., Ed.; Codon Publications: Brisbane, Australia, 2015; Volume 350, pp. 171-196.

111. Padovano, V.; Podrini, C.; Boletta, A.; Caplan, M.J. Metabolism and mitochondria in polycystic kidney disease research and therapy. Nat. Rev. Nephrol. 2018, 14, 678-687. [CrossRef]

112. Robbins, D.J.; Fei, D.L.; Riobo, N.A. The Hedgehog Signal Transduction Network. Sci. Signal. 2012,5 , re6. [CrossRef] [PubMed]

113. Ruat, M.; Hoch, L.; Faure, H.; Rognan, D. Targeting of Smoothened for therapeutic gain. Trends Pharmacol. Sci. 2014, 35, 237-246. [CrossRef] [PubMed]

114. Pietrobono, S.; Gagliardi, S.; Stecca, B. Non-canonical Hedgehog Signaling Pathway in Cancer: Activation of GLI Transcription Factors Beyond Smoothened. Front. Genet. 2019, 10, 556. [CrossRef] [PubMed]

115. Pietrobono, S.; Stecca, B. Targeting the Oncoprotein Smoothened by Small Molecules: Focus on Novel Acylguanidine Derivatives as Potent Smoothened Inhibitors. Cells 2018, 7, 272. [CrossRef]

116. Dong, X.; Wang, C.; Chen, Z.; Zhao, W. Overcoming the resistance mechanisms of Smoothened inhibitors. Drug Discov. Today 2018, 23, 704-710. [CrossRef]

117. Halls, M.L.; Cooper, D.M. Adenylyl cyclase signalling complexes-Pharmacological challenges and opportunities. Pharmacol. Ther. 2017, 172, 171-180. [CrossRef]

118. Pala, R.; Mohieldin, A.M.; Shamloo, K.; Sherpa, R.T.; Kathem, S.H.; Zhou, J.; Luan, Z.; Zheng, J.G.; Ahsan, A.; Nauli, S.M. Personalized nanotherapy by specifically targeting cell organelles to improve vascular hypertension. Nano Lett. 2019, 19, 904-914. [CrossRef]

119. Pala, R.; Mohieldin, A.M.; Sherpa, R.T.; Kathem, S.H.; Shamloo, K.; Luan, Z.; Zhou, J.; Zheng, J.-G.; Ahsan, A.; Nauli, S.M. Ciliotherapy: Remote Control of Primary Cilia Movement and Function by Magnetic Nanoparticles. ACS Nano 2019, 13, 3555-3572. [CrossRef]

120. Wang, Y.; Ho, T.G.; Franz, E.; Hermann, J.S.; Smith, F.D.; Hehnly, H.; Esseltine, J.L.; Hanold, L.E.; Murph, M.M.; Bertinetti, D.; et al. PKA-Type I Selective Constrained Peptide Disruptors of AKAP Complexes. ACS Chem. Boil. 2015, 10, 1502-1510. [CrossRef]

121. Prinz, A.; Diskar, M.; Erlbruch, A.; Herberg, F.W. Novel, isotype-specific sensors for protein kinase A subunit interaction based on bioluminescence resonance energy transfer (BRET). Cell. Signal. 2006, 18, 1616-1625. [CrossRef]

122. Wong, S.Y.; Reiter, J.F. The primary cilium at the crossroads of mammalian hedgehog signaling. Curr. Top. Dev. Boil. 2008, 85, 225-260. 